The Singapore Economic Review, Vol. 60, No. 4 (2015) 1540001 (17 pages)

(C) The Author(s)

DOI: $10.1142 / \mathrm{S} 0217590815400019$

\title{
SOME CONCEPTUAL AND METHODOLOGICAL ISSUES ON HAPPINESS: LESSONS FROM EVOLUTIONARY BIOLOGY
}

\author{
YEW-KWANG NG \\ Division of Economics \\ Nanyang Technological University, Singapore
}

Published 2 September 2015

\begin{abstract}
Despite recent intense interest, happiness studies have been impeded by some conceptual and methodological problems, including viewing happiness (well-being/welfare) as different over different persons, as relative, multi-dimensional, non-cardinally measurable, interpersonally non-comparable and using non-cardinal and interpersonally non-comparable methods of happiness measurement. Using the evolutionary biology of happiness, this paper argues that happiness is absolute, universal, and unidimensional and is also cardinally measurable and interpersonally comparable. This is needed to make choices motivated by reward (pleasure) and punishment (pain) consistent with fitness maximization. However, happiness indices obtained by virtually all existing methods of happiness measurement are largely non-cardinal and non-comparable, making the use of averaging in group happiness indices of dubious philosophical validity. A method of measuring happiness to give cardinal and interpersonally comparable indices is discussed. These may contribute towards the more scientific study of happiness that is based on sounder methodological grounds as well as yielding more useful results.
\end{abstract}

Keywords: Evolutionary biology; happiness; interpersonal comparison; measurability; well-being; welfare.

\section{Introduction}

Studies on happiness, life satisfaction, or subjective well-being (SWB) have traditionally been undertaken mainly by psychologists and sociologists. In the recent two decades or so, these studies have attracted much wider groups of researchers, including economists and neuro-scientists. Despite this wider and more intensive effort, the progress of happiness studies towards a more scientific level has been hampered by conceptual disagreements and the use of happiness measures that are largely non-comparable. This paper argues that these impediments could be at least partially removed by learning from evolutionary biology and by using a more comparable method of measurement.

A popular method of measuring happiness is to ask respondents to rate their own happiness level by choosing a number between 0 and 10. (The use of a few categories like

This is an Open Access article published by World Scientific Publishing Company. It is distributed under the terms of the Creative Commons Attribution 4.0 (CC-BY) License. Further distribution of this work is permitted, provided the original work is properly cited. 
"very happy, happy, not happy" fares no better and in fact provides even less information.) For countries that have long time-series of such happiness data like Australia and the US, the average reports have been around 7.5 for many decades, despite real per capita incomes several times higher and also much higher levels of technology and amenity for the convenience of life. However, it is possible that people now may be twice (or half) as happy (in terms of the subjective amount of happiness enjoyed) as people 80 years ago, but both groups chose an average of around 7.5 to represent their happiness levels. This may be due to an increase in the aspired or expected level/amount of happiness, leading people to use similar happiness number despite a doubling in happiness. As these two groups are different sets of people, the existing happiness measurement that is interpersonally non-comparable is difficult to uncover the real picture.

The problem is made worse by the belief by many members of the public and researchers alike that happiness and/or "the concept of happiness differs from person to person" (Guillen-Royo and Velazco, 2012, p. 264); see also McGregor and Goldsmith (1998), Uchida (2010). Another common questionable view is that "happiness is relative". This is correct in some sense as happiness is affected by relative comparison. However, many regard "the state of 'happiness' [itself] is relative" e.g., Chester (2008), making the scientific study of happiness almost impossible, if such beliefs are strictly adhered to. Yet another damaging view is "that happiness is multi-dimensional and may not be fully assessed by one measure" (Holder and Klassen, 2010, p. 426).

Until the recent interest in happiness, modern economics had long given up the study of happiness and satisfaction but concentrate on preference. However, they mostly regard preference as not cardinally measurable and not interpersonally comparable. Such views, also held by happiness researchers in other fields, are also unhelpful, to say the least, to the scientific study of happiness. For one thing, if happiness and happiness measures only have ordinal but not cardinal significance, one can only say higher or lower happiness levels, one cannot compare differences in happiness levels. This makes the widely (if not universally) used averaging of happiness levels methodologically incorrect, even if we ignore the problem of interpersonal comparison. A happiness index of 8 is higher than that of 6 , but we cannot average the two to get 7 unless happiness is cardinal and cardinally measured; see (Katzner, 1998) and (Kristoffersen, 2010) for more details on this mistake.

It is remarkable that the same scholars who regard happiness as ordinally measurable only also routinely use the averaging of happiness indices. Some scholars justify this by claiming the offsetting effects of using a large number of reports. However, such offsetting may only get rid of some biases/mistakes but not all. If happiness itself is intrinsically noncardinal, averaging is methodologically meaningless even for the same single person, offsetting or not. On the other hand, if happiness itself has cardinal significance but certain methods of measurement only give ordinally significant indices, even full offsetting may not get rid of certain biases.

For example, consider the commonly used method of rating happiness level between zero and ten. A not too happy but on balance somewhat happy individual (with net happiness normalized at say 100 for comparison) may report a figure of 6 in period 1 . If her (net) happiness triples to 300 in period 2, she may report a figure of 8 . An increase of 6 
to 8 is not three times. However, if we take 5 to represent the neutrality level with happiness offset by unhappiness and a net happiness level of zero (this is appropriate as no negative number is allowed from the restriction of 0 to 10 and from the normal usage of $50 \%$ as the passing grade in schools), 8 actually signifies a net happiness level $(8-5=3)$ three times that of $6(6-5=1)$. However, if her happiness doubles to 600 in period 3 , she cannot report a figure of 11 to give an accurate doubling of net happiness $(11-5=6)$ and may report 9 or 9.5 at most if she is sensible, as she should allow for possible further increase in happiness in the future. Thus, at least for such a case, the increase in happiness index of 1.5 points (from 8 to 9.5) may actually represent a bigger increase (from 300 to 600 ) than the increase (from 100 to 300 ) of 2 points (from 6 to 8 ). Thus, even if happiness is intrinsically cardinal as assumed in this paragraph, the method of using the $0-10$ range does not give in general a fully cardinal index, though it probably gives more information than a purely ordinal ranking. This partially cardinal nature of the commonly used measure does not seem to have been explored in the literature (e.g., Kristoffersen, 2010; Stevens, 1975), though $(\mathrm{Ng}, 2008)$ tries to capture the likely relationship between actual net happiness and reports restricted to $0-10$ by an arc-tangent curve.

Comparing the affect-balance (i.e., the excess of pleasant over unpleasant feelings) scores with the reports in the happiness or SWB scale of $0-10$, it has been found that "the zero-point of the affect-balance scale corresponds to the mid-point of the SWB scale" (Kristoffersen, 2010, p. 116). This empirical finding supports the use of 5 as the neutrality point, the existence of zero amount of (net) happiness, and the ratio-scale (full cardinality) of happiness, at least intrinsically (see the appendix).

This paper argues that the basic principles of evolutionary biology (Section 2) may be used to dispel or at least question the above-mentioned damaging views or beliefs on the non-universality, multi-dimensionality, relativity, non-cardinality and interpersonal noncomparability of happiness (Section 3). A method of measuring happiness in a cardinal and interpersonally comparable way is also suggested (Section 4). These may contribute towards the more scientific study of happiness that is based on sounder methodological grounds.

\section{Evolutionary Biology of Happiness}

Why are human individuals and those of some animal species capable of enjoyment (feeling happy) and suffering (feeling pain or unhappiness) ${ }^{1}$ Though this is a very underresearched problem, we may yet use elements of evolutionary biology to help answer it.

A precondition for affective feelings (enjoyment and suffering) is consciousness. One cannot enjoy or suffer if one is not conscious. Consciousness is a principal function of a (sufficiently advanced) brain. For humans, while our brain accounts for about 2-3\% of our body weight, it consumes no less than $20 \%$ of our total energy consumption. Though many of our brain functions are at the sub-conscious or non-conscious levels, it is clear that

\footnotetext{
${ }^{1}$ Finer distinctions made by some researchers on possible differences between pain and suffering, happiness and well-being/ welfare, and the like are ignored here.
} 
consciousness must also be energy-requiring if not much more so. We lose consciousness when our brain is not sufficiently supplied with blood. Thus, consciousness must contribute to fitness and this contribution must be more than offsetting to its disproportionate energy requirement for it to survive natural selection (or God's economizing).

How does consciousness contribute to fitness of the organism? It can do so only by affecting its activities. For example, if you are conscious of the imminent attack of a tiger but take no action to run away, such consciousness does not contribute to fitness. But why have consciousness that requires a lot of energy and then have consciousness affect activities? Why not just affect whatever the required activities (like running away) directly without the mediation of consciousness? These direct actions/reactions are probably true for many lower forms of animals? It is also true for our reflex actions like the arm withdrawal when our fingers are burned. This is the function of our spinal cord. The withdrawal happened before our conscious awareness of the withdrawal. So such actions without the mediation of consciousness are clearly feasible. Why consciousness then?

The answer is that for complex enough situations, evolution does not know in advance what actions are good for fitness. For the arm withdrawal reflex, in virtually $99.99 \%$ of cases, the best response is to withdraw. Thus, hard-wired arm withdrawal without the mediation of consciousness is best for fitness. However, the same may not be true for more complex situations. Moreover, the evolution of more species made the environment more complex and hence made simple hard-wired behavioral patterns less fitness appropriate. The number of all possible combinations of different factors that may affect the appropriate actions are astronomical. It thus became too costly to program all the appropriate actions for the huge number of different possible contingencies.

No philosophers and no scientists can explain how subjective consciousness could arise from matter (this world-knot of the mind-matter barrier is as knotty as ever, despite some presumptuous claims to have "consciousness explained"). However, if consciousness could evolve somehow, it would clearly provide the option of enhancing fitness significantly by allowing the organism to size up the situation on the spot before making such decisions as "fight or flight". If the opponent is weaker than yourself, you fight and get to eat the food; if stronger, you flee to avoid danger. More advanced species with consciousness may thus make more fitness-enhancing decisions in addition to pre-programed hard-wired reactions like the arm withdrawal. The increased in fitness may more than offset the energy costs of having consciousness. Such flexible behavior further increases the complexity of the environment, increasing the selection pressure and creating a virtuous cycle towards more complexity and rational species, partly explaining the high speed of evolution. See (Ng, 1996a) for more details.

To increase fitness through flexible choice is thus the function of consciousness. Species capable of such flexible choice is by definition plastic. The activities of non-plastic species are all pre-programmed or hard-wired to have certain fixed actions/reactions under given circumstances. Imprinting is an example of such hard-wired behavior. Hence, nonplastic species cannot possess consciousness. This is so since such consciousness would then be redundant. It would just be energy consuming without adding to fitness by making flexible choice. Even if it were to happen by chance mutation, it could not survive the 
pressure of natural selection. Thus, ignoring transient mutants, all non-plastic species are non-conscious.

With the evolution of conscious species, how did evolution or God ensure that the flexible choice guided by consciousness is consistent with the fitness of the organism? If they are rigidly pre-programmed genetically to ensure that all their activities are consistent with fitness, they are no longer plastic. As just explained above, non-plastic species cannot be conscious. The problem was cleverly solved by endowing the conscious species with a reward and punishment center. As a rule, activities consistent with fitness like eating when hungry are rewarded with pleasure and activities that are fitness reducing like injuries are punished with pain. The maximization of net happiness (excess of pleasure over pain) then serves as the criterion for trading off different activities and motives, making pleasure the "common currency" (Cabanac, 1992); see also (Broom, 2001; Ng, 1995; Rolls, 2005) on the evolution of pleasure and pain.

It is true that, according to epiphenomenalism, consciousness is just a by product or side effect without any efficacious effect on the physical world. However, such a view is inconsistent with evolutionary economy as argued above. Epiphenomenalism has not been taken very seriously since Jerry Fodor. However this is no place to go into a lengthy debate on epiphenomenalism.

To make choices in accordance with the maximization of net happiness (or welfare) consistent with fitness maximization, the amount of pleasure and pain must be related to the effects on fitness of the organism. The first principle is: Fitness-enhancing activities yield pleasure and fitness-reducing activities give rise to pain as already remarked above. Second, activities that enhance fitness more yield more pleasure and activities that reduce fitness more give rise to larger amounts of pain. This is particularly needed as the organism may face with either-or choice. When a tiger has to decide chasing after either a rabbit or a squirrel but not both, the one offering a higher expected fitness enhancement should be chosen. Similarly, as a rule and subject to the costs of effecting the feelings, an injury that is more life threatening should be more painful so that the organism takes more caution in avoiding it.

Another point strengthening the necessity of cardinality in pleasure and pain is that an organism is often faced with choices involving risk. At least for Homo sapiens, the degree of rationality in choice is highly developed. When risk is involved, rationality requires the maximization of expected utility/welfare (Ng, 1984). Such choices cannot be consistent with the maximization of expected fitness if the cardinality of the welfare values involved is not the same as (or at least cardinally equivalent to) that of fitness. As fitness is cardinally measurable, pleasure and pain or welfare values must also be cardinally measurable. (This point is shown more precisely in the appendix.)

The above basic principles derived from evolutionary biology may be used to help us dispel many misconceptions in happiness studies, as shown in Section 3.

\section{Happiness is Absolute, Universal and Uni-Dimensional}

A common belief is that happiness differs between individuals. The truth may well be that happiness itself is the same universally in its basic principle, in fact not only across 
different individuals, but also across different species capable of enjoyment and suffering, due to the common origin or functionality of these feelings across species. This is at least a likely possibility and should be taken as our default belief unless it is found to be inconsistent with some evidence. This may be justified on the methodological simplicity ground of Occam's razor and the non-necessity of useless complexity of evolutionary economy. This position is also supported by recent studies on the emergence of consciousness and affective feelings ("affective neuroscience"), showing that fundamentally similar brain structures support affective reactions in both animals (from amniotes to primates) and humans (e.g., Mashoura and Alkire, 2013). "There is now abundant experimental evidence indicating that all mammals (possibly many other vertebrates; in fact even invertebrates like crayfish have been found to have worries; see Fossat et al., 2014) have negatively and positively-valenced emotional networks concentrated in homologous brain regions that mediate affective experiences when animals are emotionally aroused....These brain circuits are situated in homologous subcortical brain regions in all vertebrates tested. Thus, if one activates FEAR arousal circuits in rats, cats or primates, all exhibit similar fear responses" (Panksepp, 2011, Abstract; see also Berridge and Kringelbach, 2011; Jorge and Vuilleumier, 2013; Lewis et al., 2014; Rickard and Vella-Brodrick, 2014).

However, even in a same species like $H$. sapiens, due to differences in individual constitution, experience, culture, education, etc., different individuals may achieve happiness differently and the same factors may affect the happiness of different individuals differently. In fact, even in this respect, individual differences have been exaggerated. Thus, after reviewing substantial research results, a veteran happiness researcher (Veenhoven, 2010b, p. 617) concludes, "These findings fit the theory that happiness depends very much on the degree to which living conditions fit universal human needs (livability theory). They do not fit the theory that happiness depends on culturally variable wants (comparison theory) or that happiness is geared by cultural specific ideas about life (folklore theory)." (Italics original; bold and underline added; see also Veenhoven, 2010a.) Similarly, the finding on the importance of good government for happiness "is apparently independent of culture" (Ott, 2010a).

Another piece of evidence in favor of universality and that cultural differences are not that important is that the many differences between immigrants and local residents are largely reduced if not eliminated in just one generation (Yann et al., 2010) (Esser, 2006, p. 38) concludes that "the second generation [of immigrants] virtually makes a jump to assimilation ... and this finding is stable across all immigrant groups, all cohorts and all periodic fluctuations." Different but related measures also show similar cross-country similarity (e.g., see Torsheim et al., 2012). It is thus not surprising that, "Even if we classify individual affective feelings into different classes such as instinctive, social, and we-world, total happiness may still be represented uni-dimensionally" (Yu and Jiang, 2012, p. 977, note 14).

As different members of the same species, we share many basic biological similarities, including what make us happy and unhappy. Strictly speaking, it is also a mistake (but a lesser one) to say that happiness is relative. Happiness and unhappiness/pain are absolute. It is just that relative standing, comparisons both to others and to one's own past, and 
adaptation are very important in affecting happiness, making people misleadingly say that "happiness is relative".

Suppose a tremor made you hurt yourself and you suffered a pain of say 10 units in time $t 1$. Then, suppose (A) you discovered that your office was only slightly damaged while many other offices in your building were severely damaged. Your sense of relief overwhelmed your sense of sympathy and hence you forget about your pain in $t 1$ and felt a positive 2 units in $t 2$. If instead of this situation A, you have (B) you discovered that your office was slightly damaged (same extent as A above) while most other offices in your building remained largely intact and no one was hurt. You felt sorry for your misfortune and your pain from $t 1$ seemed to linger and you had a negative 5 units in $t 2$. Comparing the two alternative situations in $t 2$, it is clear that relative factors affect your happiness, making you feel a positive 2 units in A while a negative 5 units in $\mathrm{B}$, though the absolute damage to your office is the same in both cases. However, while the relief feeling in $t 2$ might have made you forget about your pain in $t 1$, your negative 10 units of pain in $t 1$ remained absolute at 10 units. Similarly, your positive 2 units under alternative A or negative 5 units under alternative $\mathrm{B}$ are also absolute.

Consider, "When younger, happiness stems more from excitement; however, as one gets older, happiness stems more from feeling peaceful" (Mogilner et al., 2011). Magilner interprets this as evidence for the "Shifting Meaning of Happiness". However, it is just that the factors affecting one's happiness may differ for different persons and as one ages.

This interesting finding of Mogilner et al. is likely to be universal as well and the reason is likely to be biological. As shown by ( $\mathrm{Ng}, 1991)$, due to the cumulative nature of knowledge, it is more important for the young to learn more as their accumulated knowledge is still relatively low and the higher knowledge, if acquired, could be used longer; due to the complementarity of learning and being adventurous, it is more important for the young to be willing to be adventurous and risk-taking. Thus, we are programmed to derive high happiness from the excitement of taking adventures and risks when young. When already old, learning is no longer very important; it is then more important to avoid risks and hence older people derive more happiness from peacefulness.

If the young and the old of a same species are affected differently by the same factors, of course, different species may be capable of enjoying different amounts and different types of happiness. Obviously, a species not capable of sight cannot enjoy the joy of seeing something beautiful, similarly for a blind person. Even for the same person, the happiness she enjoys may also be of different amounts or intensities and be of different types. Beautiful sceneries and delicious tastes are different in qualia. However, ignoring the effects on future happiness and that of others, different types of happiness can be compared along a single dimension consisting in the product of average intensity and the duration of enjoyment (or the integral of intensities over the relevant time duration). Just as one may make a mistake in judging the volume of water in containers of different shapes, individuals may misjudge the actual amount of happiness; the well-known peak-end heuristic or duration neglect being a notable example. However, this difficulty does not make happiness or water not cardinally measurable uni-dimensionally in principle. In fact, the amount of 
enjoyment may be expected to be roughly proportionate to the significance to fitness, as argued in the previous section.

Many arguments/beliefs that happiness is multi-dimensional and that there are other valuable things other than happiness are based on not pursuing to the ultimate ends and are more apparent than real. For example, McMahan and Estes (2011) believe that "well-being is multifaceted (Deci and Ryan, 2008; Ryff and Singer, 2008) and is not likely to be completely captured by single instruments measuring only one aspect of positive psychological functioning" (p. 270). Instead, "four dimensions (of well-being) were identified representing the Experience of Pleasure, Avoidance of Negative Experience, Self-Development, and Contribution to Others" (p. 281). Taking (net) happiness as the excess of positive affective feelings (including pleasures) over negative ones, it is not difficult to see that these four dimensions can be reduced to one. The first two are already components of net happiness. However, putting it as the avoidance of negative experience, rather than counting negative affective feelings negatively, could be misleading in the following sense.

Negative experience counts negatively, but the avoidance as such does not count positively unless it gives rise to positive feelings such as a good sense of relief. But then that should be counted under positive affective feelings. Consider the following two alternative lives A and B. For simplicity, no effects on others and the future are involved. Life A involves positive affective feelings totaling 100 units, no avoidance of negative experience, and sustains negative affective feelings totaling 20 units. Life B involves positive affective feelings totaling 30 units, avoidance of negative experience (that almost occurred but was narrowly but successfully avoided) of 120 units (the positive feeling of relief is already included in the 30 units just mentioned), and sustains negative affective feelings of 40 units. In terms of positive feelings minus negative ones plus the avoidance of negative ones, Life B is superior at 110 units (compared to A's 80 units). However, in terms of positive minus negative feelings, Life $\mathrm{A}$ is superior at 80 units compared to B's negative 10. Clearly, avoidance as such is not valuable; it should be positive minus negative feelings that are valuable.

Ignoring misjudgment (or rather report/recollection), different types of happiness perceived by the individual concerned as being equal are equal. In this sense, different types of pleasure differ only in quantity (as determined by intensity and duration), not in quality. They differ in quality for being of different types of feelings or qualia, as the pleasure of beautiful scenery certainly differs from that of delicious taste. However, they do not differ in quality in the sense of being of higher or lower quality. This is so provided we agree to treat the effects on others and in the future as separate, even though relevant.

For example, a certain amount of pleasure from appreciating poetry (or music, reading, etc.) may be regarded as pleasure of a higher quality than the amount from drinking alcohol (or eating cakes). People tend to have such views probably due to one of or both of the following reasons or something similar. First, it may take more learning to be able to appreciate poetry (compared to alcohol or cakes) and such learning is cumulative; the appreciation now tends to improve one's ability to appreciate poetry in the future. Second, the consumption of alcohol or cakes (at least if taken to the excess) tend to produce harmful effects in the future either on the individual concerned (like gaining weight or harming the 
liver) or on others (through drunken behavior or drink-driving). Based on either one or both of these two or similar reasons, it is perfectly sensible to regard the pleasure of appreciating poetry as of higher quality than that of cake eating, or even to encourage the appreciation of poetry. However, for the purpose of measuring happiness of an individual for the current period, it certainly makes sense to concentrate on that individual and on the current period and regard the same amount of pleasure to be of the same amount of significance even if it is of different types. For one thing, the effects on the happiness of others and on the future will be reckoned with when dealing with other individuals and with the future. For another thing, this makes for clarity and steers us away from unnecessary complications. Since the effects on others and the future raise different types of issues and since, if they are probably interpreted, they do not really affect our argument, it is simpler to ignore them in the discussion below. Similarly, the ten dimensions of happiness of Huppert and So (2013) may be reduced to one.

The uni-dimensionality of happiness (or at least that happiness could be measured with a single dimension) follows from the evolutionary biology of happiness discussed in the previous section. If pleasure and pain are to guide fitness maximization, different types of such affective feelings must be capable of being translated into a uni-dimensional scale to allow comparison and choice consistent with fitness maximization. The pleasure of eating and that of having sex may be quite different in qualia, but a fox has to be able to compare them in a one-dimensional scale to guide the choice between fighting for mating with a female and chasing to eat a chicken. A lexicographical ordering like sex before food will not do. When you are too hungry, you cannot perform in sex! Food before sex will also not do; when you are not too hungry, forgoing a good opportunity to mate may reduce your fitness more than forgoing a meal. As the degree of hungriness varies continuously, you must be able to compare on a one dimensional scale to choose in a fitness-maximizing way.

In fact, we may go further and say that being able to rank on a uni-dimensional scale but without cardinal significance is also not enough. The organism must also be able to compare, at least roughly, the quantitative differences of different types of pleasure and pain in order to be able to decide, for example, how much valuable time and effort to take to avoid certain types of injuries and to invest to secure different types of rewards like food and mates. This ability may be only rudimentary for lower animals with their capability of affective sentience not very well developed. However, we should be pretty sure that, for $H$. sapiens, such ability must have been developed to a very high level. Thus, it is clearly possible for a 7 years old child to know that, for most of the time when she is neither terribly thirsty nor very full, she not only prefers eating a bowl of ice-cream to drinking a cup of water, but that the direct pleasure of eating the ice-cream is no less than 10 times that of drinking water, making pleasure fully cardinal (ratio-scale measurability). In our long history of evolution, we had been constrained more by the threat of hunger than by the lack of water. Thus, we are programmed to find food that provides energy, protein, etc. very appetizing. That this preference may lead to excessive weight gain in the very recent (in evolutionary perspective) era of plenty in developed economies is another story which does not affect our argument here. 
It is true that for $H$. sapiens evolution has advanced to a much higher level than for other species so that we are capable of language, deliberation, anticipation, planning, etc. However, these higher capabilities are facilitated by the newly developed neo-cortex that most lower species lack; the rewards of pleasure and pain are the function of lower brain regions possessed by other conscious species. In terms of the ability of reducing pleasure and pain to a common one dimensional scale, we are not less, if not much more, capable of doing so than other species. This uni-dimensional comparability has implications for the cardinally measurability and interpersonal comparability of happiness, to the consideration of which we now turn.

\section{Happiness is Cardinally Measurable and Interpersonally Comparable}

For certain economic problems like the derivation of demand curves/functions, we only have to assume that a consumer/individual can compare the desirability of different bundles of goods ordinally, i.e., the ability to rank different bundles is sufficient. The same demand function can be derived from the same set of indifference curves with different sets of cardinal utility numbers, provided that the same ranking is preserved. Thus, in this sense, cardinal utility can be assumed away on the ground of Occam's razor for such problems. However, to insist on ordinal utility only (denying the use or cardinal utility) even for other problems (such as happiness studies, social choice, optimal population, choices affecting the probabilities of survival; see $(\mathrm{Ng}, 2011)$ on the latter issue) where cardinal utilities are needed, is to commit the fallacy of misplaced abstraction.

The following is representative of the modern textbook hostility against the cardinal measurability and interpersonal comparability of utility. "There is no way that you or I can measure the amount of utility that a consumer might be able to obtain from a particular good... there can be no accurate scientific assessment of the utility that someone might receive by consuming a frozen dinner or a movie relative to the utility that another person might receive from that same good... Today no one really believes that we can actually measure utils" (Miller, 2011, pp. 436-437). There is at least one counter-example to this confident assertion - the present writer.

A probably most widely used textbook in basic economics ("sold millions of copies in more than 40 languages" by 1997) that has lived through 19 editions over 1948-2010 and written by a Nobel laureate puts it bluntly: "Economists today generally reject the notion of a cardinal, measureable utility" (Samuelson and Nordhaus, 2010, p. 89). Note that a cardinal, measureable utility is not just abstracted away as unnecessary, but rejected outright.

Another widely used intermediate microeconomic textbook example on the hostility against cardinal utility: "But how do we tell if a person likes one bundle twice as much as another? How could you even tell if you like one bundle twice as much as another? One could propose various definitions for this kind of assignment: I like one bundle twice as much as another if I am willing to run twice as far to get it, or to wait twice as long, or to gamble for it at twice the odds... Although each of them is a possible interpretation of what it means to want one thing twice as much as another, none of them appears to be an especially compelling interpretation" (Varian, 2010, pp. 57-58). 
Indeed, there is an especially compelling interpretation. Since our ultimate objective is happiness (on which see (Ng, 1999, 1990)), using the amount of happiness of the individual involved provides a perfect answer to Varian's question, if we ignore the effects on others, which is another issue (slightly touched on above). The actual amount of happiness enjoyed, but not the amount of utility as representing preference orderings only, could be used to determine well-being even in the presence of preference changes.

It is true that the strong and explicit beliefs in the non-cardinal measurability and noninterpersonal comparability of happiness and/or preference (see Ng, 1999 on the differences between the two concepts) are held mainly by economists (due to the non-necessity for demand analysis as discussed above). However, even among sociologists and psychologists who study happiness, such beliefs are also very common. For example, sociologist and veteran happiness researcher Veenhoven 'argued that happiness is measured at the ordinal level' (Kalmijn and Veenhoven, 2005; Veenhoven, 2010a, p. 612n). The common belief in the non-cardinality of happiness/utility spans the whole multi-disciplinary happiness studies. Thus, after a cross-disciplinary survey of the issue of cardinality, (Kristoffersen, 2010, p. 612n) concluded that "Many scholars (economists and others) are of the opinion that wellbeing data are strictly ordinal in nature, and tend to criticize the common tendency to treat them as cardinal measures".

Consider the following three simple alternatives faced by a person:

A: Her current situation.

B: Her current situation plus being bitten by an ant (non-poisonous one) once.

C: Her current situation plus being thrown bodily into a pool of boiling water.

Obviously, she prefers A to B and B to C. If preference/utility is purely ordinal, this is all she can say. However, even you, not being her, know that the intensity of her preference of B over C is at least many thousand times larger than that of A over B. Moreover, you may also be confident that the intensity of her preference of $\mathrm{B}$ over $\mathrm{C}$ is at least many thousand times larger than that of your preference of A over B (interpreting A and B as applied to you).

True, this is interpersonal comparison of utility regarded by (Robbins, 1937, 1938) as unscientific. In fact, this comparison is solidly based on evolutionary biology discussed in Section 2 above. An ant bite reduces her (and most individuals') fitness by a very small amount and hence induces only a small amount of pain. Being thrown bodily into boiling water threatens ones' survival and must cause great pain and intense attempt to avoid it. Though there may be some degree of interpersonal differences, these are almost certainly less significant than the huge difference between an ant bite and being thrown into boiling water. Thus, our degree of confidence in the truth of the comparison above is no less than 99.99\%, a degree envied by all empirical scientists, economists included.

Most people now know that our brain consists of two hemispheres, with the left brain controlling the right side of the body and vice versa. We do not feel this duality as our two brain hemispheres are connected by corpus callosum, making our subjective consciousness unified. However, some patients with serious epilepsy have their two brain hemispheres 
separated by cutting the connection (to reduce brain interaction). They then behave as if having two centers of consciousness or mind, with their left brain (normally controlling speech) not knowing what their right brain has seen with the left eye, if a blinder is also placed between their two eyes (Gazzaniga, 1970). Thus, two separate brain hemispheres each with independent consciousness may be unified with connection through the corpus callosum. Similarly, if our technology is advanced enough to imitate the connection through the corpus callosum, we could so connect her brain with yours. Then, she could feel your taste of ice cream and you could feel her taste of blueberries. Interpersonal comparison would become almost perfect!

While happiness is cardinally measurable and interpersonally comparable in principle, it is true that the commonly used method of happiness measures is not very cardinal and interpersonally very difficult to compare, as mentioned in Section 1 above. The lack in comparability in existing happiness measures makes happiness studies vulnerable to the criticism of doubters of happiness results such as (Johns et al., 2007; Ott, 2010b). If happiness measures could be based on more comparable methods of measurement, the critics may have less gun powder to use.

Even before we achieve the high level of neuro-technology, some interpersonal comparisons of utility and happiness are possible, beyond deductions based on evolutionary biology discussed above. ( $\mathrm{Ng}, 1996 \mathrm{~b})$ devices an interpersonally/intertemporally/interculturally comparable measure of happiness and actually use it to measure self-reported happiness levels. This is based on Edgeworth's concept of a just perceivable increment of happiness, but developed to be operational and actually used to conduct an actual survey or measurement. ${ }^{2}$ For example, an individual may prefer putting two spoons of sugar to one in a cup of coffee of given size and strength. However, she may not be able to taste any difference between 1.5 and 1.6 spoons. As the amount of sugar may be virtually continuously varied, there exist a difference that makes her just able to perceive an increment of nice feeling.

Edgeworth took it as axiomatic, or, in his words "a first principle incapable of proof", that the "minimum sensibile" or the just perceivable increments of pleasures for all persons, are equatable (Edgeworth, 1881, pp. $7 \mathrm{ff}$., pp. $60 \mathrm{ff}$.). Ng derives this result as well as the utilitarian social welfare function (SWF), that social welfare is the unweighted sum of individual utilities/welfares, from more basic axioms ( $\mathrm{Ng}, 1975)$. The main axiom is the Weak Majority Preference Criterion (WMP): For any two alternatives $x$ and $y$, if no individual prefers $y$ to $x$, and (1) if $I$, the number of individuals, is even, at least $I / 2$ individuals prefer $x$ to $y$; (2) if I is odd, at least (I-1)/2 individuals prefer $x$ to $y$ and at least another individual's utility level is not lower in $x$ than in $y$, then social welfare is higher in $x$ than in $y$.

The reason why WMP leads us to the utilitarian SWF may be explained briefly. The criterion WMP requires that utility differences sufficient to give rise to preferences of half of the population must be regarded as socially more significant than utility differences not

\footnotetext{
${ }^{2}$ The concept of using the faintest unit of pleasure as the unit of measurement may be traced back to Bentham; see Tännsjö (1998). On Edgeworth's hedonimeter and the quest to measure cardinal utility, see also Colander (2007).
} 
sufficient to give rise to preferences (or dispreferences) of another half. Since any group of individuals comprising 50\% of the population is an acceptable half, this effectively makes a just-perceivable increment of utility of any individual an interpersonally equatable (in its effect on social welfare) and hence comparable unit.

The compelling criterion of WMP makes a just perceivable increment of preference (or pleasure) interpersonally equatable not only at the individual but also at the social level. Thus, if happiness studies use this just perceivable increment of happiness as the unit of measurement (as done in $\mathrm{Ng}, 1996 \mathrm{~b}$ ), the resulting measures or values will be interpersonally/intertemporally/interculturally comparable and this will help to solve all problems of comparability (at least at the conceptual level, though practical difficulties will remain). Of course there are other ways to improve the reliability and comparability of happiness measures that have been discussed or remain to be explored. In particular, the moment-based method proposed by (Kahneman, 2000) is a particularly promising approach. Oswald and Wu (2010) provide an "objective confirmation of subjective measures of human well-being" by using the orthodox economists' method of compensating differentials. Benjamin et al. (2014) propose the use of some 'fundamental aspects', but it may be an overwhelming difficulty in avoiding overlapping (see also $\mathrm{Ng}, 2008)$.

\section{Conclusion}

In happiness studies, researchers routinely report the average values of happiness levels for many individuals (or a sample of them) for a region/nation/group and do statistical corelation studies of such average values with other variables. However, if happiness itself differs between individual, is multi-dimensional, is relative, cannot be cardinally measured and made interpersonally comparable, as commonly believed by many happiness researchers, the aggregating and/or averaging of happiness values over different individuals is methodologically dubious, to say the least. This paper shows that, using the evolutionary biology of happiness, happiness is universal, absolute, and different types of happiness can be rendered into a uni-dimensional and cardinal scale. A method of measuring the intrinsically cardinal happiness in a cardinal and interpersonally, intertemporally, and inter-culturally comparable way is also discussed. This should help to make happiness studies methodologically more valid and being capable of yielding more useful results.

\section{Appendix A. The Necessity of Cardinal Welfare for Rational Agents/Organisms}

Using indifference/preference analysis, economists generally believe that as long as higher utility/welfare values are associated with higher preference levels, choices in accordance with the maximization of utility will be the same as choices maximizing preference, with different cardinal indices for the utility function. In this sense, utility needs only be ordinal. Does this mean that utility/welfare values need not be cardinal for the maximization of 
utility/welfare to be consistent with fitness maximization, even though fitness itself is cardinal? This appendix shows that, at least when choices involving risk are involved, as almost always true in the real world of uncertainty, welfare values for rational agents have to be cardinal and similar to fitness values in their cardinality for rational choices to be consistent with expected fitness maximization.

For simplicity, let us be content with the illustration of the central point that can be seen to be applicable more generally. Consider that a rational organism (as happiness studies are currently virtually exclusively concerned with $H$. sapiens, this rationality assumption is certainly valid) is faced with the choice between two actions $a$ and $b$, with two possible states of nature $x$ and $y$ with equal probability of $50 \%$ each (again purely for simplicity without real loss of generality). Let $F(j, k)$ and $W(j, k)$ be the fitness and welfare values of actions $j=a, b$ and states of nature $k=x, y$ respectively. Consider a specific case, without real loss of generality (since it is obvious that the point made with the specific numbers here also applies more generally) where

$$
F(b, y)=22>F(a, y)=20>F(a, x)=10>F(b, x)=5 .
$$

The maximization of expected fitness requires the choice of action $a$. If $W(j, k)$ is equal to $F(j, k)$ for all values of $j, k$, the required expected fitness maximization choice will coincide with that of the maximization of expected welfare values. As $F$ is cardinal, so is $W$. However, if $W(j, k)$ is made only having the same ordinal ranking but not the same cardinal values as $F(j, k)$, in general, the maximization of expected welfare values by rational agents/organisms (required to satisfy compelling rationality axioms; see $\mathrm{Ng}, 1984$ ) does not in general coincide with that of expected fitness maximization. For example if we have

$$
W(b, y)=50>W(a, y)=20>W(a, x)=10>W(b, x)=5,
$$

the ordering of the various welfare values for all the four outcomes under consideration is exactly the same as that of the fitness values in (A.1) above. However, expected welfare maximization in this case dictates the choice of action $b$, contrary to the requirement of expected fitness maximization.

Obviously, in order that the maximization of expected welfare always dictates the same action as that for expected fitness maximization, the welfare values under different outcomes have either to be the same as the fitness values or are some linear transformation of the latter, i.e., have to be not only having the same ranking, but also having the same cardinal numbers unique up to a linear transformation. This makes welfare values cardinal but not yet in a ratio scale. For the latter (full cardinality), we need to pin point the point of zero welfare. This is the point when an organism (individual) feels neither pleasure nor pain. For most people, this is the case when the individual is not doing anything enhancing or detrimental to fitness, directly or indirectly through expectation. Why is a zero welfare value associated with zero implication for fitness? This is so because it is costly (energy consumption) to produce either pleasure or pain. Thus, activities with no implication for fitness should neither be penalized nor rewarded (for more details, see $\mathrm{Ng}, 1995$ ). 


\section{References}

Benjamin, DJ, O Heffetz, Kimball and N Szembrot (2014). Beyond happiness and satisfaction: Toward well-being indices based on stated preference. American Economic Review, 104(9), 2698-2735.

Berridge, KC and ML Kringelbach (2011). Building a neuroscience of pleasure and well-being. Psychology of Well-Being: Theory, Research and Practice, 1(3).

Broom, DM (2001). Evolution of pain, in David Morton and Lord Soulsby. Pain: Its Nature and Management in Man and Animals, Royal Society of Medicine International Congress Symposium Series, pp. 17-25.

Cabanac, M (1992). Pleasure: The common currency. Journal of Theoretical Biology, 155(2), 173-200.

Chester, D (2008). Positively conscious: An enlightened look at life. AuthorHouse, 304.

Colander, D (2007). Edgeworth's hedonimeter and the quest to measure utility. Journal of Economic Perspectives, 21(2), 215-225.

Deci, EL and RM Ryan (2008). Hedonia, eudaimonia, and well-being: An introduction. Journal of Happiness Studies, 9(1), 1-11.

Edgeworth, FY (1881). Mathematical Psychics: An Essay on the Application of Mathematics to the Moral Sciences. C. K. Paul. London, UK.

Esser, H (2006). Migration, Language and Integration. WZB.

Fossat, P et al. (2014). Anxiety-like behavior in crayfish is controlled by serotonin. Science, 344 (6189), 1293-1297.

Gazzaniga, MS (1970). The Bisected Brain. New York: Appleton-Century-Crofts, xii, p. 172.

Guillen-Royo, M and J Velazco (2012). Happy villages and unhappy slums? Understanding happiness determinants in Peru. In Happiness Across Cultures, H Selin and G Davey, pp. 253-270. Springer, The Netherlands.

Holder, M and A Klassen (2010). Temperament and happiness in children. Journal of Happiness Studies, 11(4), 419-439.

Huppert, FA and TTC So (2013). Flourishing across Europe: Application of a new conceptual framework for defining well-being. Social Indicators Research, 110(3), 837-861.

Johns, H, P Ormerod and Institute of Economic Affairs (2007). Happiness, Economics and Public Policy. Institute of Economic Affairs.

Jorge, A and P Vuilleumier (eds.) (2013). The Cambridge Handbook of Human Affective Neuroscience. Cambridge University Press. Cambridge, UK.

Kahneman, D (2000). Evaluation by moments: Past and future. Choices, Values, and Frames, 693-708.

Kalmijn, W and R Veenhoven (2005). Measuring inequality of happiness in nations: In search for proper statistics. Journal of Happiness Studies, 6(4), 357-396.

Katzner, DW (1998). Time, Ignorance, and Uncertainty in Economic Models. University of Michigan Press. Michigan, USA.

Kristoffersen, I (2010). The metrics of subjective wellbeing: Cardinality, neutrality and additivity*. Economic Record, 86(272), 98-123.

Lewis, GJ, R Kanai, G Rees and TC Bates (2014). Neural correlates of the 'good life': Eudaimonic well-being is associated with insular cortex volume. Social Cognitive and Affective Neuroscience, 9(5), 615-618.

Mashoura, GA and MT Alkire (2013). Evolution of consciousness: Phylogeny, ontogeny, and emergence from general anesthesia, www.pnas.org/cgi/doi/10.1073/pnas.1301188110.

McGregor, SLT and EB Goldsmith (1998). Expanding our understanding of quality of life, standard of living, and well-being. Journal of Family and Consumer Sciences, 90(2), 2-6. 
McMahan, EA and D Estes (2011). Measuring lay conceptions of well-being: The beliefs about well-being scale. Journal of Happiness Studies, 12(2), 267-287.

Miller, RL (2011). Economics Today, sixteenth edition. Pearson. New York, USA.

Mogilner, C, SD Kamvar and J Aaker (2011). The shifting meaning of happiness. Social Psychological and Personality Science, 2(4), 395-402.

$\mathrm{Ng}$, Y-K (1975). Bentham or Bergson? Finite sensibility, utility functions and social welfare functions. The Review of Economic Studies, 42(4), 545-569.

$\mathrm{Ng}$, Y-K (1984). Expected subjective utility: Is the Neumann-Morgenstern utility the same as the Neoclassical's? Social Choice and Welfare, 1(3), 177-186.

Ng, Y-K (1990). Welfarism and utilitarianism: A rehabilitation. Utilitas, 2(02), 171-193.

$\mathrm{Ng}$, Y-K (1991). The paradox of the adventurous young and the cautious old: Natural selection vs. rational calculation. Journal of Theoretical Biology, 153(3), 339-352.

Ng, Y-K (1995). Towards welfare biology: Evolutionary economics of animal consciousness and suffering. Biology and Philosophy, 10(3), 255-285.

$\mathrm{Ng}$, Y-K (1996a). Complex niches favour rational species. Journal of Theoretical Biology, 179(4), 303-311.

Ng, Y-K (1996b). Happiness surveys: Some comparability issues and an exploratory survey based on just perceivable increments. Social Indicators Research, 38(1), 1-27.

$\mathrm{Ng}$, Y-K (1999). Utility, informed preference, or happiness: Following Harsanyi's argument to its logical conclusion. Social Choice and Welfare, 16(2), 197-216.

$\mathrm{Ng}$, Y-K (2008). Happiness studies: Ways to improve comparability and some public policy implications. Economic Record, 84(265), 253-266.

$\mathrm{Ng}$, Y-K (2011). Consumption tradeoff vs. catastrophes avoidance: Implications of some recent results in happiness studies on the economics of climate change. Climatic Change, 105(1), $109-127$.

Oswald, AJ and S Wu (2010). Objective confirmation of subjective measures of human well-being: Evidence from the USA. Science, 327(5965), 576-579.

Ott, J (2010a). Greater happiness for a greater number: Some non-controversial options for governments. Journal of Happiness Studies, 11(5), 631-647.

Ott, J (2010b). Happiness, economics and public policy: A critique. Journal of Happiness Studies, 11(1), 125-130.

Panksepp, J (2011). Cross-species affective neuroscience decoding of the primal affective experiences of humans and related animals. PLOS ONE, 6(9), e21236, doi: 10.1371/journal. pone.0021236.

Rickard, NS and DA Vella-Brodrick (2014). Changes in well-being: Complementing a psychosocial approach with neurobiological insights. Social Indicators Research, 117(2), 437-457.

Robbins, L (1937). An Essay on the Nature and Significance of Economic Science. Ludwig von Mises Institute.

Robbins, L (1938). Interpersonal comparisons of utility: A comment. The Economic Journal, 48(192), 635-641.

Rolls, ET (2005). Emotion Explained. Oxford University Press. Oxford, UK.

Ryff, CD and BH Singer (2008). Know thyself and become what you are: A eudaimonic approach to psychological well-being. Journal of Happiness Studies, 9(1), 13-39.

Samuelson, PA and WD Nordhaus (2010). Economics, Nineteenth edition. McGraw-Hill/Irwin. New York, USA.

Stevens, SS (1975). Psychophysics: Introduction to its Perceptual, Neural, and Social Prospects. Transaction Publishers. New Jersy, USA.

Tännsjö, T (1998). Hedonistic Utilitarianism, Edinburgh: Edinburgh University Press. 
Torsheim, T, O Samdal, M Rasmussen, J Freeman, R Griebler and W Dür (2012). Cross-national measurement invariance of the teacher and classmate support scale. Social Indicators Research, 105(1), 145-160.

Uchida, Y (2010). A holistic view of happiness: Belief in the negative side of happiness is more prevalent in Japan than in the United States. Psychologia, 53(4), 236-245.

Varian, HR (2010). Intermediate Microeconomics: A Modern Approach. W.W. Norton \& Company. New York, USA.

Veenhoven, R (2010a). Greater happiness for a greater number. Journal of Happiness Studies, 11(5), 605-629.

Veenhoven, R (2010b). How universal is happiness. International Differences in Well-being, 328-350.

Yann, A, D Christian, G Albrecht and M Alan (2010). The economic situation of first and secondgeneration immigrants in France, Germany and the United Kingdom. Economic Journal, 120(542), F4-F30.

Yu, HC and L Jiang (2012). A theory of consumption and happiness: The mental-force-field hypothesis. China Economic Quarterly, 11(3), 969-996. 